\title{
$\mathrm{UNLV} \mid \underset{\text { LIBRARIES }}{\mathrm{UNIVRSTT}}$
}

Electrical and Computer Engineering Faculty Publications

\section{Observation of the Visible Absorption Spectrum of $\mathrm{H} 2 \mathrm{O}+$}

\author{
Biswajit Das \\ University of Nevada, Las Vegas, dasb@unlv.nevada.edu \\ John W. Farley \\ University of Nevada, Las Vegas, farley@physics.unlv.edu
}

Follow this and additional works at: https://digitalscholarship.unlv.edu/ece_fac_articles

Part of the Chemical Engineering Commons, Electrical and Computer Engineering Commons, and the Nuclear Engineering Commons

\section{Repository Citation}

Das, B., Farley, J. W. (1991). Observation of the Visible Absorption Spectrum of H2o+. Journal of Chemical Physics, 95 8809-8815.

https://digitalscholarship.unlv.edu/ece_fac_articles/373

This Article is protected by copyright and/or related rights. It has been brought to you by Digital Scholarship@UNLV with permission from the rights-holder(s). You are free to use this Article in any way that is permitted by the copyright and related rights legislation that applies to your use. For other uses you need to obtain permission from the rights-holder(s) directly, unless additional rights are indicated by a Creative Commons license in the record and/ or on the work itself.

This Article has been accepted for inclusion in Electrical and Computer Engineering Faculty Publications by an authorized administrator of Digital Scholarship@UNLV. For more information, please contact digitalscholarship@unlv.edu. 


\section{AIP $\begin{gathered}\text { mesoumalot } \\ \text { chemical Physics }\end{gathered}$}

\section{Observation of the visible absorption spectrum of $\mathrm{H} 2 \mathrm{O}+$}

Biman Das and John W. Farley

Citation: J. Chem. Phys. 95, 8809 (1991); doi: 10.1063/1.461215

View online: http://dx.doi.org/10.1063/1.461215

View Table of Contents: http://jcp.aip.org/resource/1/JCPSA6/v95/i12

Published by the AIP Publishing LLC.

Additional information on J. Chem. Phys.

Journal Homepage: http://jcp.aip.org/

Journal Information: http://jcp.aip.org/about/about_the_journal

Top downloads: http://jcp.aip.org/features/most_downloaded

Information for Authors: http://jcp.aip.org/authors






\title{
Observation of the visible absorption spectrum of $\mathrm{H}_{2} \mathrm{O}^{+}$
}

\author{
Biman Das ${ }^{\text {a) }}$ and John W. Farley \\ Physics Department, University of Nevada, Las Vegas, Nevada 89154
}

(Received 3 June 1991; accepted 9 September 1991)

\begin{abstract}
The $\widetilde{A}^{2} \widetilde{A}_{1}-\widetilde{X}^{2} \widetilde{B}_{1}$ system of $\mathrm{H}_{2} \mathrm{O}^{+}$has been observed, using laser absorption spectroscopy in a velocity-modulated discharge. A total of 78 transitions between 14794 and $15475 \mathrm{~cm}^{-1}$ have been observed with an uncertainty ( $1 \mathrm{SD}$ ) of $0.02 \mathrm{~cm}^{-1}$, including 76 transitions in the $(0,7,0)-(0,0,0)$ band and 2 in the $(0,8,0)-(0,0,0)$ band. This species is important for cometary astronomy, and intriguing for molecular physics because of its prominent Renner-Teller interaction. Careful measurements were made of the relative intensities of the absorption lines, which were measured to an accuracy of $13 \%$ (1 SD). This is the first observation of the $\widetilde{A}-\widetilde{X}$ transition in absorption; all previous data were obtained in emission with conventional grating spectroscopy. The transition frequencies of our new data are in good agreement with previous work, and have improved accuracy. The new data have definite rejection of the interfering lines from excited neutral $\mathrm{H}_{2}$ that plagued previous work. Compared with previous work, the new data have the first quantitative measurement of intensities. The ratio of the Franck-Condon factors $I_{8} / I_{7}=0.99 \pm 0.43$ has been measured for the first time, where $I_{v}=\mathrm{FCF}\left[\left(0, v^{\prime}, 0\right)-(0,0,0)\right]$.
\end{abstract}

\section{INTRODUCTION}

The water cation, $\mathrm{H}_{2} \mathrm{O}^{+}$, has been studied for a number of years by cometary astronomers. It has been observed in comet tails, the upper atmosphere, and the laboratory. It is an important species for astrophysics, atmospheric sciences, and chemistry. In this paper, we briefly review past work on this species, describe our experimental apparatus and procedure, present our new data, and compare it with the best previous data.

\section{PREVIOUS WORK ON $\mathrm{H}_{2} \mathrm{O}^{+}$}

Much of the early interest in $\mathrm{H}_{2} \mathrm{O}^{+}$came from astronomical observation, often progressing in close association with laboratory studies. In 1950 Whipple ${ }^{1}$ proposed that the heads of comets consist primarily of solid $\mathrm{H}_{2} \mathrm{O}$. The cation is generated by photoionization of neutral $\mathrm{H}_{2} \mathrm{O}$ by sunlight. The observation of $\mathrm{H}_{2} \mathrm{O}^{+}$in comet tails was an important confirmation of Whipple's hypothesis. Neutral $\mathrm{H}_{2} \mathrm{O}$ has no electronic emission spectrum because its excited electronic states predissociate, and hence detection of the cation is the only way, albeit indirect, of detecting the species in visible emission. Unidentified features in the spectrum of comet Kohoutek, reported by several observers, including Benvenuti and Wurm, ${ }^{2}$ Herbig, ${ }^{3}$ and Wehinger and Wyckoff, ${ }^{4}$ were tentatively identified as $\mathrm{H}_{2} \mathrm{O}^{+}$by Herzberg and Lew, ${ }^{5}$ based on the laboratory observation of the $\widetilde{A}-\widetilde{X}$ electronic emission spectrum by Lew and Heiber. ${ }^{6}$ A more complete report and conclusive identification of $\mathrm{H}_{2} \mathrm{O}^{+}$in the spectrum of Comet Kohoutek was given by Wehinger et al. ${ }^{7}$ The ion was also identified in the spectrum of Comet Bradford ${ }^{8}$ and in the upper atmosphere. ${ }^{9}$ The most detailed laboratory study in the visible was reported by Lew, ${ }^{10}$ who observed the emission spectrum with a conventional grating instrument.

\footnotetext{
") Present address: Chemistry Department, Univèrsity of Kentucky, Lexington, Kentucky 40506.
}

Experimental studies of the ground electronic state include photoelectron spectroscopy, ${ }^{11,12}$ infrared velocitymodulation spectroscopy, ${ }^{13-16}$ laser magnetic resonance spectroscopy, ${ }^{17}$ electron-spin resonance (ESR) in a cryogenic matrix, ${ }^{18}$ and Coulomb explosion. ${ }^{19}$ The lifetime of the vibrationally excited $\left(0, v_{2}^{\prime}, 0\right)$ levels of the excited $\widetilde{A}^{2} \widetilde{A}_{1}$ state has been measured ${ }^{20}$ to be $10.5 \mu \mathrm{s}$ for $v_{2}^{\prime}=12-15$, corresponding to an oscillator strength $f \sim 10^{-3}$. In addition, there have been a number of theoretical studies of the ground electronic state. ${ }^{21-25}$

The ground $\widetilde{X}^{2} \widetilde{B}_{1}$ state of $\mathrm{H}_{2} \mathrm{O}^{+}$is sharply bent, while the excited $\widetilde{A}^{2} \widetilde{A}_{1}$ state is quasilinear, with a low barrier to linearity. In a linear configuration, there is a double degeneracy in the electronic state from $\pi$ orbitals. When the molecule bends, it lifts the degeneracy of the $\pi$ orbitals. The resulting electronic potential curve as a function of the bending angle is shown schematically in Fig. 1. In both the ground and excited electronic states, the potential curve is Wshaped, with minima corresponding to a bent molecule. The two electronic states coincide at the nonequilibrium linear configuration. ${ }^{26}$ This leads to the Renner-Teller interaction, ${ }^{27}$ i.e., a strong interaction between the bending vibration and the electronic motion. Under these circumstances the Born-Oppenheimer approximation breaks down, because the electronic wave functions are strongly dependent upon the bending angle, and vibronic states within the two electronic states are strongly mixed. In the excited $\widetilde{A}$ state the barrier to linearity is low, and therefore only the first few vibrational levels will be below the barrier. These levels will be strongly perturbed by the Renner-Teller effect, whereas above the barrier the energy levels should be much more regular.

\section{EXPERIMENTAL METHOD}

Molecular ions have been relatively poorly explored until recently, in part because conventional absorption spectroscopy, which has proven so fruitful for neutral molecules, 




FIG. 1. Electronic energy levels of the $\mathrm{H}_{2} \mathrm{O}^{+}$ion as a function of the bend angle. Both the ground $X$ state and the excited $A$ state have W-shaped curves. The two electronic energy levels are degenerate when the molecule passes through a linear configuration. This produces a breakdown of the Born-Oppenheimer approximation via the Renner-Teller effect.

is difficult to apply to molecular ions. The typical densities of molecular ions in a discharge are orders of magnitude lower than the densities of neutral molecules. Consequently, the absorption from ions can be swamped by the much stronger absorption from neutrals.

In 1983, Gudeman et $a .^{28}$ introduced the technique of velocity-modulation spectroscopy, shown schematically in Fig. 2, which allows a high degree of suppression of the interfering neutral signal. The sample is a discharge driven by a plasma generator operating at a frequency $f$ in the range 10 $100 \mathrm{kHz}$. The audio frequency electric field inside the discharge modulates the velocity of the ions at the discharge frequency $f$. This causes a synchronous Doppler shift in the ion absorption signal, producing a dispersion-shaped signal which can be detected by a lock-in at frequency $f$. In contrast, the neutrals do not experience velocity modulation. Instead, they are density-modulated at frequency $2 f$ and ideally produce no signal at frequency $f$. The combination of an ac discharge and lock-in detection thus allows a high degree of discrimination in favor of the ions and against the neutrals. This technique has been used to measure the spectrum of a large number of positive and negative molecular

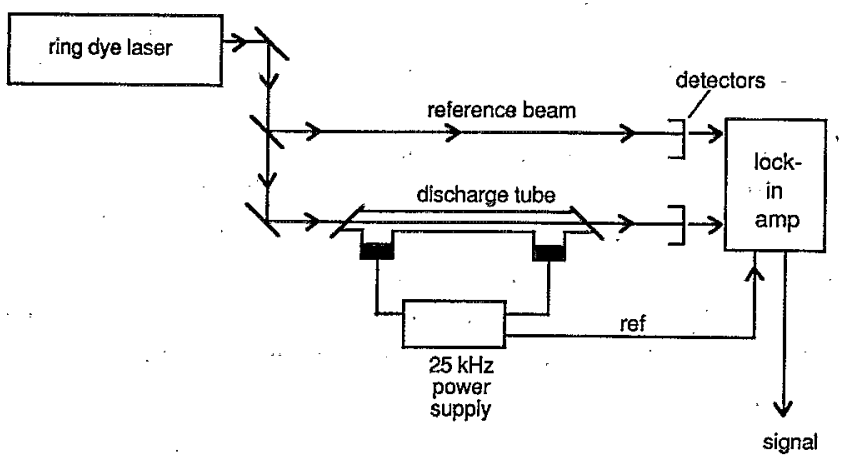

FIG. 2. Schematic of the experimental apparatus. A single-mode laser beam from a ring dye laser is absorbed by $\mathrm{H}_{2} \mathrm{O}^{+}$ions in a velocity-modulated discharge. The dual-beam technique provides noise cancellation that is necessary for the observation of signals. ions by the research groups headed by Saykally, ${ }^{29} \mathrm{Oka}^{30}$ Hirota, ${ }^{31}$ Blom, ${ }^{32}$ McKellar and Amano, ${ }^{33}$ and Davies. ${ }^{34}$ A recent improvement in the velocity-modulation techniques $^{35}$ has been developed in our laboratory.

The theory of the resonance line shape in velocitymodulated spectroscopy has been developed by one of us (J.W.F.) and published separately. ${ }^{36}$ The present paper is solely concerned with line centers and intensities; we hope to perform a more detailed analysis at a later date.

\section{EXPERIMENTAL APPARATUS}

The velocity-modulated technique is implemented in our laboratory at the University of Nevada, Las Vegas with a Pyrex discharge tube, ${ }^{37}$ cooled by a closed loop of circulating distilled water, which in turn is cooled by tap water with a homemade copper coil heat exchanger. The use of distilled water as a cooling medium is advisable because tap water in Las Vegas, drawn from the Colorado River, is extremely hard (over $200 \mathrm{ppm}$ as $\mathrm{CaCO}_{3}$ ). Isopropyl alcohol or methanol is added to the distilled water to prevent the growth of algae. The discharge is driven by an ENI Plasmaloc PL2 plasma generator and an ENI RS816T impedancematching transformer. The stability of the discharge was greatly enhanced by the use of a series assembly of seven ballast resistors, each $100 \mathrm{~W}, 1 \mathrm{k} \Omega$, resulting in $7 \mathrm{k} \Omega$ for the assembly. A $10 \Omega$ resistor in the ground line provides a diagnostic signal.

The discharge conditions were varied to maximize the signal strength. Optimum pressures of the source gases were 8-9 Torr $\mathrm{He} / 100$ mTorr $\mathrm{O}_{2} / 100 \mathrm{mTorr} \mathrm{H}_{2}$. The pressures were measured by an MKS Baratron model $111 \mathrm{~A}$ capacitive manometer, with a 10 Torr range. The signal was rather sensitive to the partial pressures of $\mathrm{H}_{2}$ and $\mathrm{O}_{2}$. The strategy of mixing $\mathrm{H}_{2}$ and $\mathrm{O}_{2}$ to produce $\mathrm{H}_{2} \mathrm{O}^{+}$was used by Oka and co-workers, ${ }^{14}$ who reported that a discharge of $\mathrm{H}_{2} \mathrm{O}$ in He produces $\mathrm{H}_{3} \mathrm{O}^{+}$as the dominant ion, not $\mathrm{H}_{2} \mathrm{O}^{+}$. This observation is understandable in terms of gas-phase ionmolecule reactions, because $\mathrm{H}_{3} \mathrm{O}^{+}$is a terminal ion, isoelectronic to neon, while $\mathrm{H}_{2} \mathrm{O}^{+}$is an intermediate ion.

The discharge power supply typically delivered 300$350 \mathrm{~W}$ and $400 \mathrm{~mA}$ current $\mathrm{p}-\mathrm{p}$ at a frequency of $25 \mathrm{kHz}$. About half the power was dissipated in the discharge. A Coherent 699-21 ring dye laser, oscillating on DCM dye, was pumped by a Coherent Model Innova- $10 \mathrm{Ar}^{+}$pump laser that produced $6 \mathrm{~W}$ at a wavelength of $488 \mathrm{~nm}$. The typical single-mode ring dye laser power level was $200-500 \mathrm{~mW}$, depending on wavelength. The useful wavelength range using this dye is $625-680 \mathrm{~nm}$, or $14700-16000 \mathrm{~cm}^{-1}$.

The output of the dye laser was sampled by two beam splitters, producing a sample beam that traversed the discharge tube and a reference beam. Both beams fall upon silicon Schottky barrier photodiodes (United Detector Technology model PIN-10), operated in photoconductive mode. Their signals are converted to voltages and amplified in a homemade preamplifier, whose circuit is shown in Fig. 3. The detector/preamp combination has a responsivity of $2.5 \mathrm{~V} / \mathrm{mW}$ at $633 \mathrm{~nm}$, and a bandwidth of at least $50 \mathrm{kHz}$. The typical intensity of each laser beam is $2 \mathrm{~mW}$ to avoid saturating the detector. 


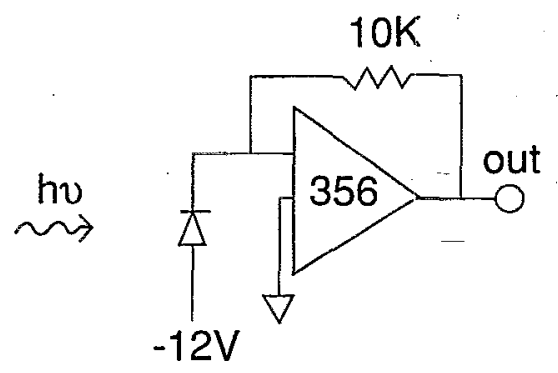

FIG. 3. Circuit diagram of the photodetector/preamplifier combination.

The intensity ratio of the two laser beams was adjusted using a variable attenuator in the reference beam to produce equal signal levels at the input to the lock-in. The signals are subtracted and demodulated by a PARC model 5209 lock-in amplifier, whose time constant was typically $1 \mathrm{~s}$. The two detectors are mounted in a common aluminum block to minimize the temperature differential between the two detectors. This noise subtraction technique ${ }^{38}$ results in a reduction in the noise level by about a factor of 80-100, a factor that was essential in order to observe the resonances. Typical data are shown in Fig. 4. A typical signal level for a strong transition was $100 \mu \mathrm{V} \mathrm{p}-\mathrm{p}_{\text {, }}$ or $16 \mathrm{ppm}$ of the $6 \mathrm{~V} \mathrm{dc}$ level from the detector. The noise (typically $2-3 \mu \mathrm{V}$ ) arises primarily from uncancelled intensity fluctuations in the dye laser. The signal represents an absorption of $100 \mu \mathrm{V} / 6$ $\mathrm{V}=16 \mathrm{ppm}$ over the $80 \mathrm{~cm}$ path length of the discharge, or an absorption coefficient of $2 \times 10^{-7} \mathrm{~cm}^{-1}$. The minimum detectable signal is $2 \mu \mathrm{V} / 6 \mathrm{~V}$ or $3 \times 10^{-7}$ over the $80 \mathrm{~cm}$ path length, or a fractional absorption of $4 \times 10^{-9} \mathrm{~cm}^{-1}$.

Considerable care was taken to measure the intensities reproducibly, and to minimize the effects of drifts in discharge conditions. A strong transition, the $5_{23}-5_{15}$ line in the $\Delta$ subband of the $(0,7,0)-(0,0,0)$ band, occurring at $15154.88 \mathrm{~cm}^{-1}$, was chosen as the reference transition. A transition whose intensity was unknown was measured, and its intensity ratioed to the reference transition. The reference transition was measured before and after the unknown transition. No more than 30 min elapsed between successive measurements of the reference transition. The unknown transition was ratioed to the closest (in time) measurement of the reference transition. Thus no more than 15 min separate the measurements of the unknown and reference transi-

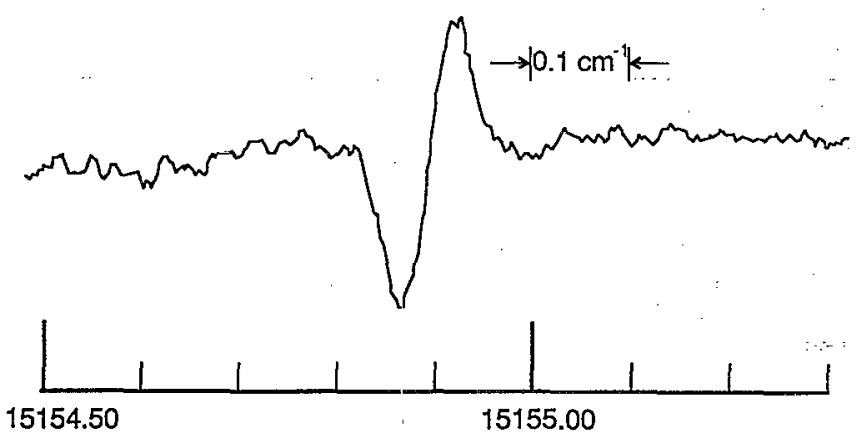

FIG. 4. Typical experimental absorption signal of $\mathrm{H}_{2} \mathrm{O}^{+}$. tion. By repeating intensity measurements on different days, and obtaining two, three, or four independent measurements of each transitions, we estimate the uncertainty to be $13 \%$ ( 1 SD). This is discussed in more detail below.

The transitions observed are shown in Table I, which also lists the experimental data of Lew. ${ }^{10}$ The transitions appear in pairs, where the upper (lower) transition, denoted $F_{1}\left(F_{2}\right)$, corresponds to $J=N+1 / 2(J=N-1 / 2)$. All but two of the new data are in the $(0,7,0)-(0,0,0)$ band, in which the $v_{2}$ refers to the bending mode. The two exceptional data are in the $(0,8,0)-(0,0,0)$ band, which were barely accessible in our laser range.

The uncertainty in the line centers of the new measurement is $0.02 \mathrm{~cm}^{-1}$, limited by the readout of the Burleigh wavemeter and the precision in alignment of the beams from the ring laser and the wavemeter reference laser. The uncertainty cited in the previous measurement ${ }^{10}$ was $0.05 \mathrm{~cm}^{-1}$. The largest deviation between the new and old measurements is $0.028 \mathrm{~cm}^{-1}$, and the rms deviation over the data set is $0.013 \mathrm{~cm}^{-1}$, indicating that the nominal uncertainties are conservative.

\section{INTENSITIES}

Table I also lists our measurement of the intensities. The intensity of each transition was measured more than once, referencing each to the reference transition as described above. Of the 78 transitions listed in Table $\mathrm{I}$, the intensities of 11 transitions were measured twice, 59 transitions were measured thrice, and 7 transitions were measured four times. This totals 77 transitions, with the last transition being the reference transition itself. For each transition, the measurements were averaged, and the mean and standard deviation $^{39}$ reported in Table I.

The standard deviation is listed in Table $\mathrm{I}$ in the same units as the transition intensity, a relative scale with the intensity of the reference transition arbitrarily set at 100 . Because of our measurement procedure, there is no listing for the reference transition itself. Instead, fluctuations in the intensity of the reference transition will manifest themselves as greater uncertainties in the intensities of other transitions, and thus be distributed thoughout the data set.

More important than the standard deviation as a figure of merit is the relative standard deviation, also listed in Table I: the standard deviation of a transition as a percentage of the intensity of the transition. If denotes the fractional uncertainty with which the intensity of a given transition can be measured.

In order to examine the quality of the data, a standard data set has been compiled by excluding the following from Table I: (1) the reference transition, because the uncertainty in its measurement is not measured directly; (2) all blended transitions, because their conclusion would degrade the quality of the data set; and (3) the two data in the $(0,8,0)-$ $(0,0,0)$ band, because their intensities are affected by a different Franck-Condon factor. The standard data set contains 31 transitions in the $\Sigma$ subband and 40 in the $\Delta$ subband.

Figure 5 shows a histogram of the relative standard deviations of the data in the standard data set. Except for two 
TABLE I. Transition line centers and intensities of the $\mathrm{H}_{2} \mathrm{O}^{+}$transitions. The transitions are classified according to subband, with $\Sigma$, $\Pi, \Delta, \Phi$ corresponding to $K_{a}^{\prime}=0,1,2,3$. Even values of $v_{2}^{\prime}$ give rise to $\Pi, \Phi, \ldots$ subbands; while odd values of $v_{2}^{\prime}$ give rise to $\Sigma, \Delta, \ldots$ subbands. Within a subband, each branch is denoted by $\Delta K_{a}, \Delta N, K a^{\prime \prime}, K c^{\prime \prime}$. Each transition is denoted by $N^{\prime}, K a^{\prime}, K c^{\prime}-N^{\prime \prime} K a^{\prime \prime}, K c^{\prime \prime}$, where $K_{a}(K c)$ refers to the projection of $N=J-S$ upon the $A(C)$ axis in the prolate (oblate) limit.

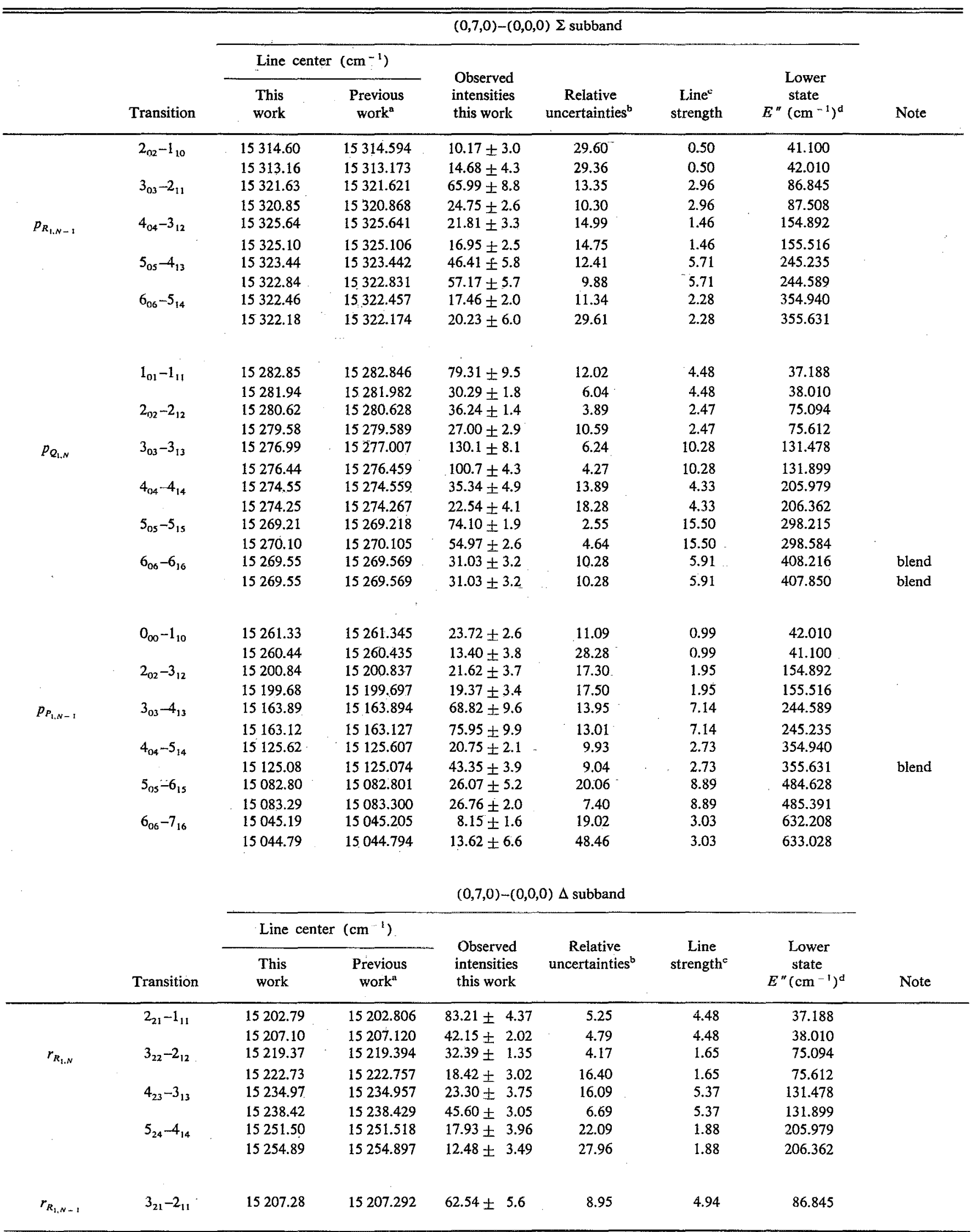




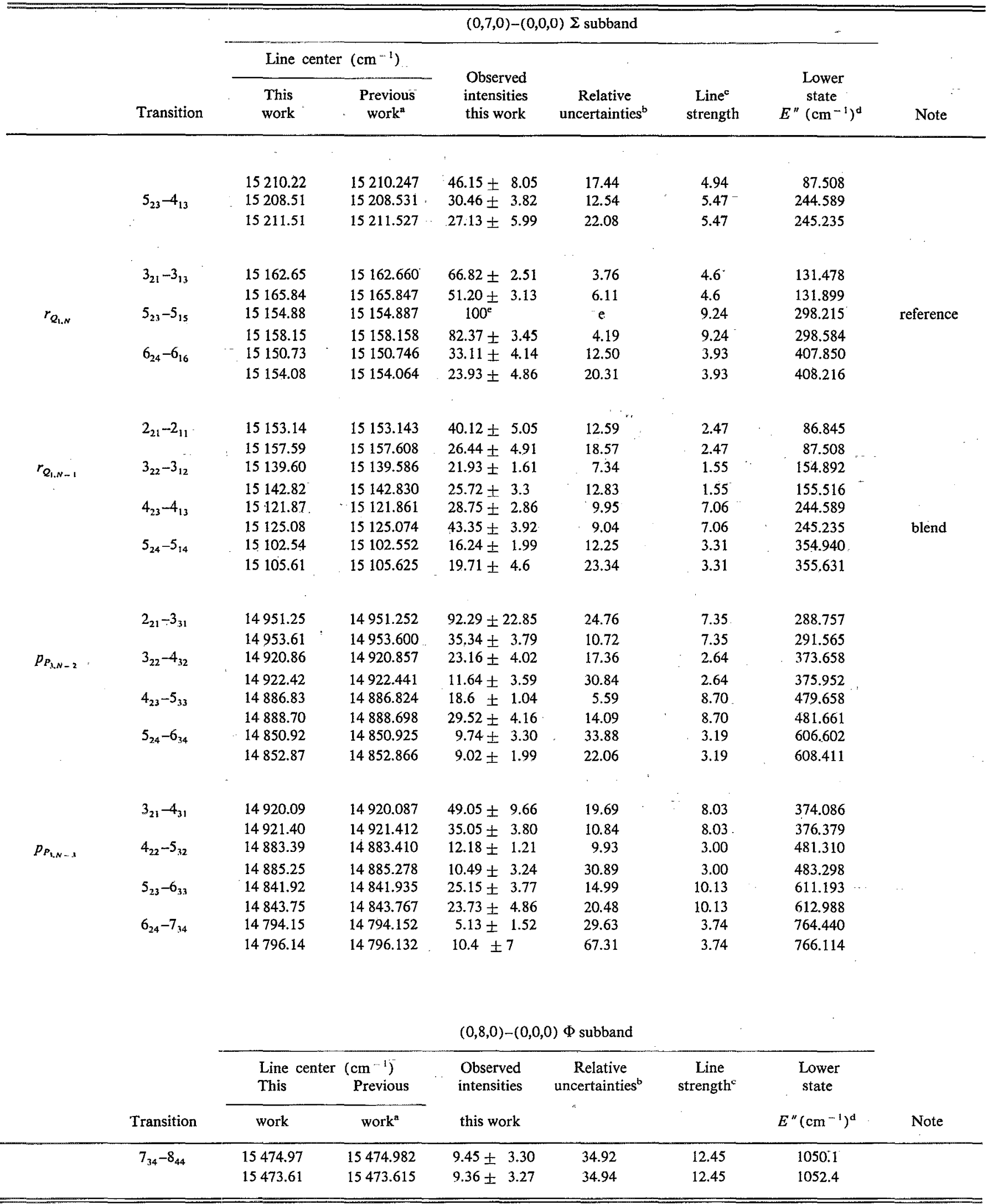

"Lew, Ref. 10. Uncertainty is $\pm 0.05 \mathrm{~cm}^{-1}$.

"The relative uncertainty is the uncertainty in the line intensity as a percentage of the intensity.

"The calculated line strength includes the statistical weight, from which the line intensity can be calculated by the inclusion of a Boltzmann factor. From Table I of Lew, Ref, 11.

${ }^{\circledR}$ Lew, Ref. 10.

'Not applicable because this is the reference line. 


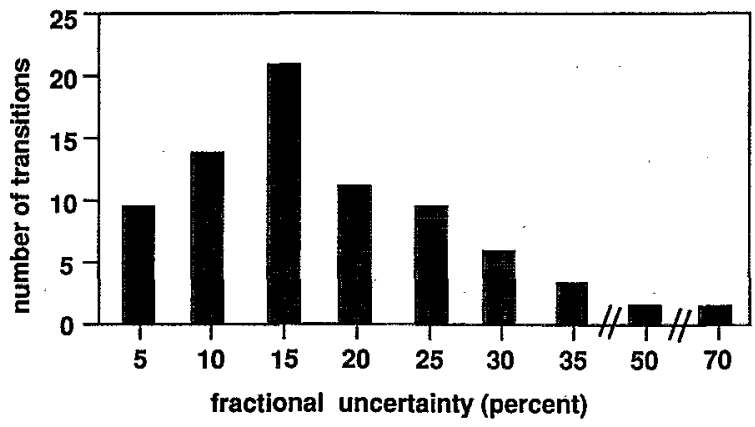

FIG. 5. Histogram of the relative standard deviations in the standard data set. The standard data set consists of all the data in Table I, excluding the reference transition, all blended transitions, and the two transitions in the $(0,8,0)-(0,0,0)$ band. The relative standard deviation is the standard deviation divided by the intensity of the transition. The abscissa plots the number of transitions with relative standard deviation in the $0-5 \%$ range as 5 , $5 \%-10 \%$ as 10 , etc.

outlying data points, the data appear to be under good statistical control, with a smooth Poisson-like distribution. The median value of the relative standard deviation is $13.35 \%$. If the data set is restricted to the $\Sigma$ subband, the median relative standard deviation is $13.35 \%$; if the data set is restricted to the $\Delta$ subband, the median standard deviation is $14.5 \%$. Since there are no important differences between the two subbands, the standard data set combines the two subbands, and the recommended value for the data set as a whole is $13 \%$.

\section{DETERMINATION OF THE ROTATIONAL TEMPERATURE OF THE GROUND STATE}

The relative standard deviation is an index of the reproducibility of the intensity of a given transition. Other information requires a different data analysis. If the populations in the lower $\widetilde{X}$ state are described by a Boltzmann distribution, the experimental intensities $I_{\exp }$ are described by

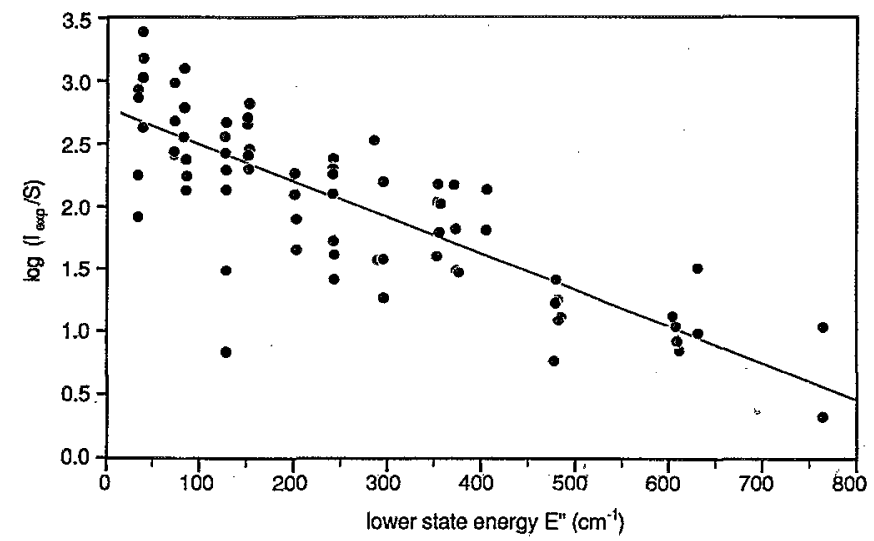

FIG. 6. Boltzmann plot of the intensities of the transitions as a function of the energy of the lower state. The ordinate is the $\ln (I / S)$, where $I$ is the experimental intensity from Table $\mathrm{I}$, and $S$ is the calculated line strength from Lew, Ref. 10. The abscissa is the energy $E^{\prime \prime}$ of the lower state in wave numbers. The data are restricted to the standard data set discussed in Fig. 5 caption. A least-squares fit to the data reveals the rotational temperature of $494 \pm 38 \mathrm{~K}$.

$$
I_{\exp }=A \text { FCF } S \exp \left(-E^{\prime \prime} / k T\right),
$$

where $A$ is a normalization constant, FCF is the FranckCondon factor appropriate to all transitions within a given vibrational band, $S$ is the calculated line strength (including the statistical weights), $E$ " is the energy of the lower state, and $T$ is the temperature. Therefore a plot of $\ln \left(I_{\text {exp }} / S\right)$ vs $E^{\prime \prime}$ yields a straight line whose slope is $-1 / k T$. In Fig. 6, we have displayed the standard data set, plotting $\ln \left(I_{\text {exp }} / S\right)$ as a function of $E$ ". The values of the line strength $S$ were reported by Lew ${ }^{10}$ using the Asymmetric Rotor Program of Birss and Ramsay. ${ }^{40} S$ includes the statistical weights, and is the same for absorption and emission. A standard leastsquares fit to the line

$$
\ln \left(I_{\exp } / S\right)=a+b E^{\prime \prime},
$$

with all transitions given equal weight, yields optimized parameters $a=2.7896 \pm 0.0736$ and $b=-0.0029147$ $\pm 0.000223 \mathrm{~cm}$. This yields a temperature $T=494 \pm 38 \mathrm{~K}$, a reasonable value for a gaseous discharge.

\section{MEASUREMENT OF FRANCK-CONDON FACTOR}

The extraction of the rotational temperature was performed on the standard data set, which excludes the two transitions observed in the $(0,8,0)-(0,0,0)$ band. This was a deliberate choice, because there is an additional factor in the $(0,8,0)-(0,0,0)$ band, a ratio of Franck-Condon factors. The latter two transitions have virtually the same intensity and the same energy $E^{\prime \prime}$, and hence their average value will be used, an intensity of $9.405 \pm 35 \%$. The intensity of the transitions in the 8-0 band can be combined with the temperature to calculate the ratio of the Franck-Condon Factors.

If the Franck-Condon factor for the $(0,7,0)-(0,0,0)$ band, denoted $I_{7}$, were the same as $I_{8}$, then the two data points for the the 8-0 band would lie on the same curve as the points of the standard data set. The expected intensity could

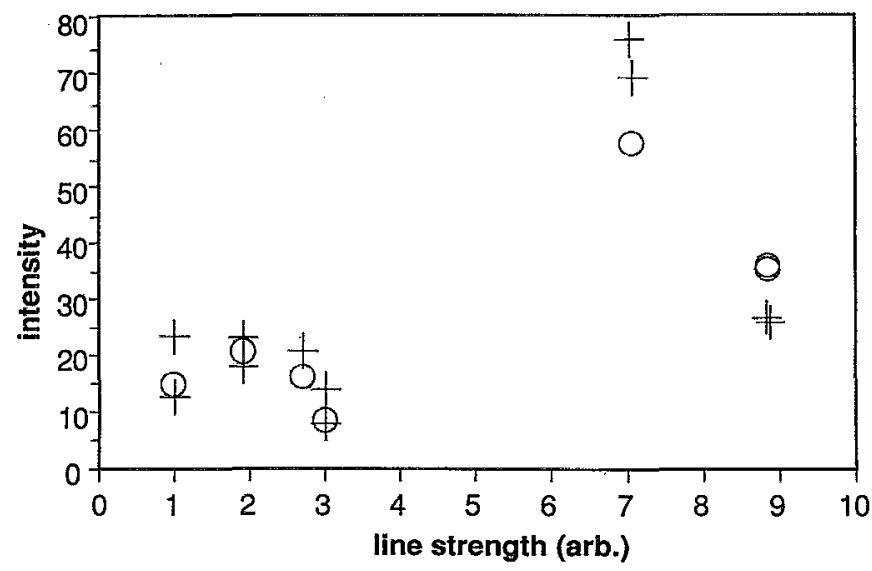

FIG. 7. Measured and calculated intensities for a series of closely related resonances for which the intensity varies dramatically with quantum number. The data are from the $p_{P_{1, x-1}}$ series of transitions of the $\Sigma$ subband of the $(0,7,0)-(0,0,0)$ band. The cross denotes the experimental intensity, while the circle denotes a fitted intensity, which incorporates the calculated line strength. The calculation follows the experimental intensities. 
be obtained by extrapolating Eq. (1) using $E^{\prime \prime}=1050$ $\mathrm{cm}^{-1}$, obtaining $I_{\exp } / S=0.7628+27.7 \%-21.7 \%$. The actual intensity, from Table $I$, is $9.405 / 12.45$ $=0.7554 \pm 35 \%$. The ratio of the Franck-Condon factors is thus $I_{8} / I_{7}=0.99+0.45-0.41$. In view of the nearequality of the positive and negative uncertainties, it is reasonable to average the positive and negative uncertainties to obtain $0.99 \pm 0.43$. This result does not depend upon any assumption of equality between vibrational and rotational temperatures, because the only temperature that matters is the rotational temperature in the ground electronic and vibrational state.

Comparison can be made with the calculation of Lew, using an asymmetric rotor computer program of Birss and Ramsay. ${ }^{40}$ A natural test case is a sequence of transitions in which the intensities vary dramatically with quantum number. In Fig. 7 we have plotted the data in the $p_{P_{1, N-1}}$ transitions of the $\Sigma$ subband of the $(0,7,0)-(0,0,0)$ band. The calculated line strengths vary from 0.99 to 8.89 , a factor of 9 . This is thus a fairly stringent test of the calculation. Plotted are the experimental intensities, $I_{\text {exp }}$, marked with a cross and a fitted number, $I_{\mathrm{fit}}$ defined by $I_{\mathrm{fit}}=\operatorname{Sexp}\left(a+b E^{\prime \prime}\right)$, where $S$ is the line strength from Table I. Figure 7 shows that the calculation follows the experimental numbers quite well. This enhances confidence in the calculation incorporated in the Asymmetric Rotor Program of Birss and Ramsay.

In the previous work of Lew, the temperature was not under good experimental control. In his subsequent work ${ }^{41}$ on $\mathrm{D}_{2} \mathrm{O}^{+}$, Lew reported a non-Boltzmannian distribution. In general, absorption spectroscopy allows better control over the population distribution than does emission spectroscopy.

\section{CONCLUSION}

We have shown that it is possible to observe the absorption spectrum of an ion that is not a terminal ion, despite the weak absorption oscillator strength, and despite the use of a relatively noisy dye laser. Accurate measurements were made of the relative absorption cross sections. If the absorption cross section of even a single transition can be measured absolutely, then the entire manifold will be known absolutely. We expect to continue this work into the Renner-Teller region by continuing our measurements farther to the infrared, where conventional emission spectroscopy ${ }^{10}$ eventually fails because of the large number of lines from excited $\mathrm{H}_{2}$.

\section{ACKNOWLEDGMENTS}

Support for this work is gratefully acknowledged from the NSF under Grant Nos. PHY-8719090 and PHY8903387, from NASA under Contract No. NAGW-1585, and by Contract No. F04611-87-K-0211 from the Air Force Astronautics Laboratory. We also wish to acknowledge valuable technical assistance from Jun Li and Hans Dieter Tholl, and useful conversations with John L. Hardwick.

${ }^{1}$ F. L. Whipple, Astrophys. J. 111, 375 (1950).

${ }^{2}$ P. Benvenuti and K. Wurm, Astron. Astrophys. 31, 121 (1974).

${ }^{3}$ G. Herbig, IAU Circ. No. 2596 (1973).

${ }^{4}$ P. Wehinger and S. Wyckoff, IAU Circ. No. 2626 (1973).

${ }^{5}$ G. Herzberg and L. Lew, Astron. Astrophys. 31, 123 (1974).

${ }^{6}$ H. Lew and I. Heiber, J. Chem. Phys. 58, 1246 (1973).

${ }^{7}$ P. A. Wehinger, S. Wyckoff, G. Herbig, G. Herzberg, and H. Lew, Astrophys. J. 190, L43 (1974).

${ }^{8}$ P. Wehinger and S. Wyckoff, Astrophys. J. 192, L41 (1974).

${ }^{9}$ G. Herzberg, Ann. Geophys. 36, 605 (1980).

${ }^{10}$ H. Lew, Can. J. Phys. 54, 2028 (1976).

${ }^{11}$ C. R. Brundle and D. W. Turner, Proc. R. Soc. London, Ser. A 307, 27 (1968).

${ }^{12}$ A. W. Potts and W. C. Price, Proc. R. Soc. London, Ser. A 326, 181 (1972).

${ }^{13}$ M. W. Crofton, R. S. Altman, M.-F. Jagod, B. D. Rehfuss, and T. Oka, in Proceedings of the Molecular Spectroscopy Symposium, Columbus, Ohio, June 1985 (unpublished).

${ }^{14}$ B. M. Dinelli, M. W. Crofton, and T. Oka, J. Mol. Spectrosc. 127, 1 (1988).

${ }^{15}$ D.-J. Liu, W.-C. Ho, and T. Oka, J. Chem. Phys. 87, 2442 (1987).

${ }^{16}$ Philip R. Brown, Paul B. Davies, and Ross J. Stickland, J. Chem. Phys. 91, 3384 (1989).

${ }^{17}$ S. E. Strahan, R. P. Mueller, and R. J. Saykally, J. Chem. Phys. 85, 1252 (1986).

${ }^{18}$ L. B. Knight and J. Steadman, J. Chem. Phys. 78, 5940 (1983).

${ }^{19}$ D. Zajfman, A. Belkacem, T. Graber, E. P. Kanter, R. E. Mitchell, R. Naaman, Z. Vager, and B. J. Zabransky, J. Chem. Phys. 94, 2543 (1991).

${ }^{20} \mathrm{G}$. R. Moehlmann, K. K. Bhutani, F. J. de Heer, and S. Tsurubuchi, Chem. Phys. 31, 273 (1978).

${ }_{21}$ J. A. Smith, P. Jorgensen, and Y. Ohrn, J. Chem. Phys. 62, 1285 (1975).

${ }^{22}$ Ch. J. Jackels, J. Chem. Phys. 72, 4873 (1980).

${ }^{23}$ P. J. Fortune, B. J. Rosenburg, and A. C. Wahl, J. Chem. Phys. 65, 2201 (1976).

${ }^{24}$ A. Degli Esposti, D. G. Lister, P. Palmieri, and C. Degli Esposti, J. Chem. Phys. 87, 6772 (1987).

${ }^{25}$ B. Weis, S. Carter, P. Rosmus, H.-J. Werner, and P. J. Knowles, J. Chem. Phys. 91, 2818 (1989).

${ }^{26}$ J. Michael Hollas, High Resolution Spectroscopy (Butterworths, London, 1982), pp. 401-3.

${ }^{27}$ G. Herzberg and E. Teller, Z. Phys. Chem. B 21, 410 (1933); R. Renner, Z. Phys. 92, 172 (1934); J. A. Pople and H. C. Loguet-Higgins, Mol. Phys. 1, 372 (1958).

${ }^{28}$ C. S. Gudeman, M. H. Begemann, J. Pfaff, and R. J. Saykally, Phys. Rev. Lett. 50, 727 (1983)

${ }^{29}$ J. Owrutsky, N. Rosenbaum, L. Tack, M. Gruebele, M. Polak, and R. J. Saykally, Philos. Trans. R. Soc. London, Ser. A 324, 97 (1988).

${ }^{30}$ T. Oka, Proc. R. Soc. London, Ser. A 324, 81 (1988).

${ }^{31}$ K. Kawaguchi and E. Hirota, J. Chem. Phys. 84, 2953 (1986), using magnetic field modulation.

${ }^{32}$ S. Civis, C. E. Blom, and P. Jensen, J. Mol. Spectrosc. 138, 69 (1989).

${ }^{33}$ T. Amano, Phil. Trans. R. Soc. London, Ser. A 324, 163 (1988).

${ }^{34}$ P. B. Davies, Proc. R. Soc. London, Ser. A 324, 121 (1988).

${ }^{35}$ Guang Lan, Hans Dieter Tholl, and John W. Farley, Rev. Sci. Instrum. 62, 944 (1991).

${ }^{36}$ John W. Farley, J. Chem. Phys. 95, 5990 (1991).

${ }^{37}$ Suppliers were Curtis Technology, 10346 Roselle St., San Diego, CA 92121, and the glass shop at the University of Nevada, Reno.

${ }^{38}$ David J. Nesbitt, Hrvoje Petek, Christopher S. Gudeman, C. Bradley Moore, and Richard J. Saykally, J. Chem. Phys. 81, 5281 (1984).

${ }^{39} \mathrm{SD}^{2}=(N-1)^{-1} \Sigma\left(x_{l}-\mu\right)^{2}$. There is occasional confusion in the literature about whether the appropriate denominator should be $N$ or $N-1$. See, Philip R. Bevington, Data Reduction and Error Analysis for the Physical Sciences (McGraw-Hill, New York, 1969), pp. 18-20.

${ }^{40}$ F. W. Birss and D. A. Ramsay, Comp. Phys. Commun. 38, 83 (1984).

${ }^{41}$ H. Lew and R. Groleau, Can. J. Phys. 65, 739 (1987). 